\title{
Photodynamic Diagnosis of Hepatocellular Carcinoma Using 5-Aminolevulinic Acid
}

\author{
MASUMI NISHIMURA, YASUTOSHI MURAYAMA, KYOICHI HARADA, YOSUKE KAMADA, RYO MORIMURA, \\ HISASHI IKOMA, DAISUKE ICHIKAWA, HITOSHI FUJIWARA, KAZUMA OKAMOTO and EIGO OTSUJI \\ Division of Digestive Surgery, Department of Surgery, Kyoto Prefectural University of Medicine, Kyoto, Japan
}

\begin{abstract}
Backgtound/Aim: Since hepatocellular carcinoma (HCC) has a high recurrence rate, accurate diagnosis of its location and curative resection is important to improve survival. This study evaluated the utility of photodynamic diagnosis (PDD) using 5-aminolevulinic acid (5-ALA) for HCC. Materials and Methods: We used two human hepatoma cell lines (HuH-7 and Hep G2). Cells were treated with 5-ALA for $4 \mathrm{~h}$. 5-ALA-induced fluorescence was then examined under a fluorescence microscope. We designed hepatoma mouse models, with mice receiving an intraperitoneal injection of 5-ALA. After $4 \mathrm{~h}$, their liver tumors were removed and examined under a fluorescence microscope. We also analyzed 12 HCC patients who underwent curative liver resection. The patients were administered 5-ALA orally before surgery. The excised livers were sectioned and examined by fluorescence microscopy. Results: In vitro and in vivo, red fluorescence of protoporphyrin IX (PpIX) was observed in tumors. In 11 of 12 patients, red fluorescence was observed in their HCC. The tumor of only one patient did not exhibit red fluorescence because it had been necrosed by transcatheter arterial chemoembolization (TACE). Conclusion: Red fluorescence of PpIX was observed in hepatoma cells, tumors of HCC mouse models and HCC of patients. PDD of HCC using 5-ALA is simple and may be useful for real-time diagnosis during liver resection.
\end{abstract}

Hepatocellular carcinoma (HCC) is a common malignant tumor in Asian countries (1). Despite recent improvements

Correspondence to: Yasutoshi Murayama, MD, Ph.D., Division of Digestive Surgery, Department of Surgery, Kyoto Prefectural University of Medicine, 465 Kajii-cho, Kamigyou-ku, Kyoto 6028566, Japan. Tel: +81 752515527, Fax: +81 752515522 e-mail: murayama@koto.kpu-m.ac.jp

Key Words: Hepatocellular carcinoma, 5-aminolevulinic acid, photodynamic diagnosis, protoporphyrin IX. in diagnostic imaging and therapeutic strategies for HCC (2), the recurrence rate of $\mathrm{HCC}$ is still high. Several studies have reported that the recurrence rate of $\mathrm{HCC}$ after curative liver resection is $50-60 \%$ at 3 years and $70-100 \%$ at 5 years (39). For long-term survival, complete removal of the tumor is one of the most important factors in surgical oncology. Although the methods have progressed for diagnostic imaging, such as computed tomography (CT) and magnetic resonance imaging (MRI), it is difficult to accurately diagnose small and early-stage lesions preoperatively.

Fluorescence diagnosis has recently received a lot of attention as a powerful tool for early detection of malignant lesions. 5-aminolevulinic acid (5-ALA) is a precursor of heme and metabolized to fluorescent protoporphyrin IX (PpIX). Although PpIX is rapidly metabolized to nonfluorescent heme in normal cells, PpIX accumulates in malignant cells because of increased activity of porphobilinogen deaminase and decreased activity of ferrochelatase (10-14). PpIX emits strong red fluorescence at a peak of $635 \mathrm{~nm}$ with blue light excitation at $405 \mathrm{~nm}$. Photodynamic diagnosis (PDD) using 5-ALA has been used clinically in neurosurgery and urology (15-18). We have previously reported that PDD using 5-ALA is useful to detect lymph node metastasis and peritoneal dissemination of colon and gastric cancers (19-22).

In this study, we evaluated the utility of PDD using orally administered 5-ALA for HCC.

\section{Materials and Methods}

Cell lines and cultures. Two human hepatoma cell lines (HuH-7 and Hep G2) from the Riken cell bank (Tokyo, Japan) were used in this study. The cells were cultured in Dulbecco's modified Eagle's medium (Nacalai Tesque, Kyoto, Japan) with $10 \%$ fetal bovine serum, $100 \mathrm{U} / \mathrm{ml}$ penicillin and $100 \mu \mathrm{g} / \mathrm{ml}$ streptomycin at $37^{\circ} \mathrm{C}$ in a humidified atmosphere with $5 \% \mathrm{CO}_{2}$. HuH-7 cells, used for in vivo experiments, stably expressed enhanced green fluorescent protein (EGFP) by transient transfection of the EGFP gene and selection using $1 \mathrm{mg} / \mathrm{ml} \mathrm{G} 418$ (Wako Pure Chemical Industries, Osaka, Japan). 
Table I. Patients' characteristics.

\begin{tabular}{|c|c|c|c|c|c|c|c|c|}
\hline Case & Age (years) & Gender & Virus infection & Pathological diagnosis & Serosal invasion & Vascular invasion & Background liver & Fluorescence \\
\hline 1 & 61 & Male & $\mathrm{C}+$ & $\mathrm{HCC}$ & s0 & vp0, vv0, va0 & $\mathrm{LC}$ & + \\
\hline 2 & 71 & Male & NBNC & $\mathrm{HCC}$ & s0 & vp0, vv0, va0 & $\mathrm{CH}$ & + \\
\hline 3 & 77 & Male & NBNC & $\mathrm{HCC}$ & s0 & $\mathrm{vp} 0, \mathrm{vv0}, \mathrm{va} 0$ & $\mathrm{CH}$ & + \\
\hline 4 & 66 & Male & $\mathrm{C}+$ & Total necrosis & - & - & $\mathrm{CH}$ & - \\
\hline 5 & 52 & Female & $\mathrm{C}+$ & $\mathrm{HCC}$ & s0 & vp0, vv0, va0 & $\mathrm{LC}$ & + \\
\hline 6 & 51 & Male & $\mathrm{B}+$ & $\mathrm{HCC}$ & s0 & vp0, vv0, va0 & $\mathrm{CH}$ & + \\
\hline 7 & 68 & Female & $\mathrm{B}+$ & $\mathrm{HCC}$ & s0 & vp0, vv0, va0 & $\mathrm{CH}$ & + \\
\hline 8 & 65 & Male & $\mathrm{C}+$ & $\mathrm{HCC}$ & s0 & $\mathrm{vp} 1, \mathrm{vv0}, \mathrm{va} 0$ & $\mathrm{CH}$ & + \\
\hline 9 & 48 & Male & $\mathrm{C}+$ & $\mathrm{HCC}$ & s0 & $\mathrm{vp} 0, \mathrm{vv0}, \mathrm{va} 0$ & LC & + \\
\hline 10 & 67 & Male & $\mathrm{C}+$ & $\mathrm{HCC}$ & s0 & $\mathrm{vp} 0, \mathrm{vv0}, \mathrm{va} 0$ & $\mathrm{CH}$ & + \\
\hline 11 & 66 & Female & $\mathrm{B}+$ & $\mathrm{HCC}$ & s0 & $\mathrm{vp} 0, \mathrm{vv0}, \mathrm{va} 0$ & $\mathrm{CH}$ & + \\
\hline 12 & 73 & Male & NBNC & $\mathrm{HCC}$ & s0 & vp0, vv0, va0 & $\mathrm{CH}$ & + \\
\hline
\end{tabular}

NBNC, Non-B, non-C hepatitis; LC, liver cirrhosis; $\mathrm{CH}$, chronic hepatitis; $\mathrm{HCC}$, hepatocellular carcinoma; $\mathrm{B}+$, B hepatitis-positive; $\mathrm{C}+, \mathrm{C}$ hepatitispositive.

Fluorescence microscopy analyses. Cells were plated at a density of $1 \times 10^{6}$ cells in $35-\mathrm{mm}$ dishes. After incubation for $72 \mathrm{~h}$, the cells were treated with $1 \mathrm{mM}$ 5-ALA for $3 \mathrm{~h}$ and 5-ALA fluorescence (excitation: $440 \mathrm{~nm}$; emission: 575-675 nm) was examined under an inverted fluorescence microscope (IX81; Olympus, Tokyo, Japan).

Animal model. All animal experiments were performed according to the standard guidelines for animal experiments of Kyoto Prefectural University of Medicine, Kyoto, Japan. Five-week-old female $\mathrm{BALB} / \mathrm{c}$ nude mice were used in this study. EGFPexpressing HuH-7 cells $\left(5 \times 10^{6}\right)$ were injected into the spleen of nude mice under general anesthesia. After 4 weeks, nude mice received an intraperitoneal injection of $250 \mathrm{mg} / \mathrm{kg} \mathrm{5-ALA}$. At $4 \mathrm{~h}$ after injection, the mice were sacrificed and their liver tumors were removed and observed by microscopy.

Patients. This study was approved by the institutional ethics committee and performed at the University Hospital of Kyoto Prefectural University of Medicine from November 2012 to April 2014. We analyzed 12 HCC patients who were preoperatively diagnosed by radiological examinations. All patients had undergone curative liver resection at our hospital. The patients provided informed consent preoperatively. The exclusion criteria included the presence of porphyria and a history of allergy.

5-ALA administration. 5-ALA hydrochloride (COSMO BIO Co., Ltd., Tokyo, Japan) at 15-20 $\mathrm{mg}$ per $\mathrm{kg}$ of body weight was administered orally to each patient $3 \mathrm{~h}$ before surgery. After surgery, the excised livers were sectioned and examined under a stereomicroscope.

Fluorescence observations and pathological examination. Fluorescence was observed under a stereoscopic microscope (SZX12; Olympus, Tokyo, Japan) equipped with a color chargecoupled digital (CCD) camera (DP71; Olympus) and mercury lamp (U-LH100HG; Olympus). Emitted light from the mercury lamp was filtered through a 405 $\pm 10 \mathrm{~nm}$ band-pass filter (D405/20x; Chroma Technology Corp., Rockingham, VT, USA) to provide the excitation light. The fluorescent emission at wavelengths longer than $430 \mathrm{~nm}$ was transmitted through a long-pass filter (HQ430LP; Chroma Technology Corp.) and detected by the CCD camera. We used a spectral analytical system consisting of a stereoscopic microscope equipped with an intensified multichannel spectrophotometer (MCPD-7000; Otsuka Electronics, Osaka, Japan) for spectral analysis. The pathological diagnosis and classification of resected HCC tissues were performed according to the General Rules for the Clinical and Pathological Study of Primary Liver Cancer (23).

\section{Results}

Stereomicroscopic imaging analyses of hepatoma cell lines in vitro. All fluorescence images were obtained under identical conditions, including the photomultiplier voltage, acquisition time and excitation light intensity. As shown in Figure 1, red fluorescence of PpIX was observed in both hepatoma cell lines (HuH-7 and Hep G2) treated with 5-ALA.

Stereomicroscopic imaging analyses of the hepatoma mouse model. To determine whether 5-ALA administration can specifically visualize hepatoma, we employed a mouse model of human hepatoma. This model developed liver tumors that were microscopically visible within 4 weeks after injection of EGFP-expressing $\mathrm{HuH}-7$ cells into the spleen of nude mice. At $4 \mathrm{~h}$ after intraperitoneal injection of 5-ALA, mice were sacrificed and their liver tumors were removed. The removed tumors were subjected to both white light and fluorescence imaging. Red fluorescence was observed in tumors with EGFP fluorescence (Figure 2). We confirmed that PpIX had accumulated in the liver tumors and red fluorescence were observed in the mouse model.

Analyses of 12 HCC patients who underwent curative liver resection. The characteristics of the 12 patients are provided in Table I. There were nine men and three women with a 
A

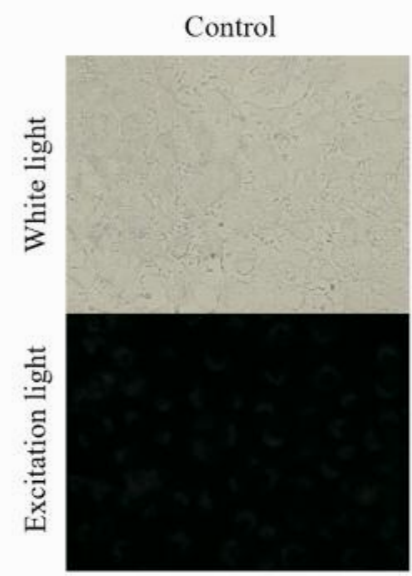

$\mathrm{HuH}-7$

With ALA treatment

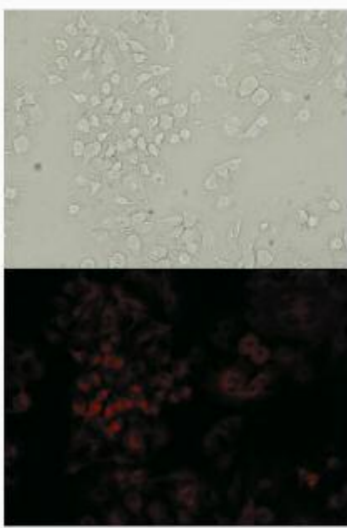

B

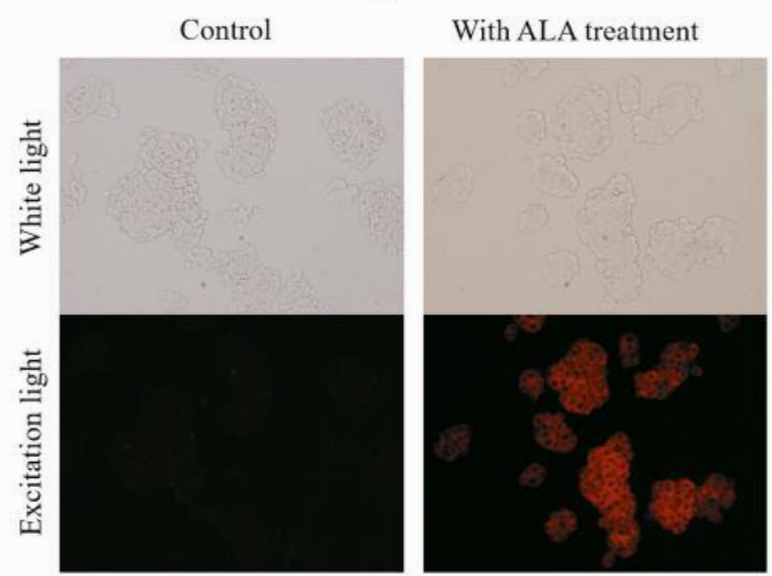

Figure 1. Stereomicroscopic imaging analyses of hepatoma cell lines (HuH-7: (A); HepG2: (B)) in vitro. Imaging was performed under white light and excitation light (excitation: $440 \mathrm{~nm}$; emission: 575-675 $\mathrm{nm}$ ). Red fluorescence of protoporphyrin IX (PpIX) was observed in both hepatoma cell lines treated with 5-aminolevulinic acid (5-ALA) under excitation light.
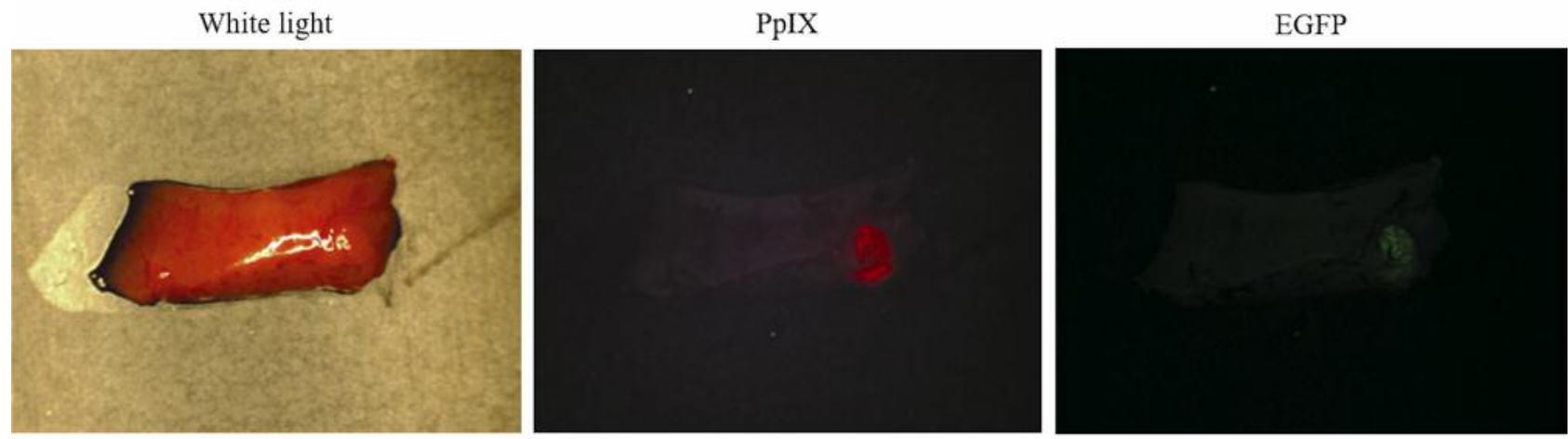

Figure 2. Stereomicroscopic imaging analyses in the hepatoma mouse model. This model developed hepatomas that were microscopically visible within 4 weeks after injection of enhanced green fluorescent protein (EGFP)-expressing $\mathrm{HuH-7}$ cells into the spleen. Red fluorescence was observed in tumors with EGFP fluorescence.

White light

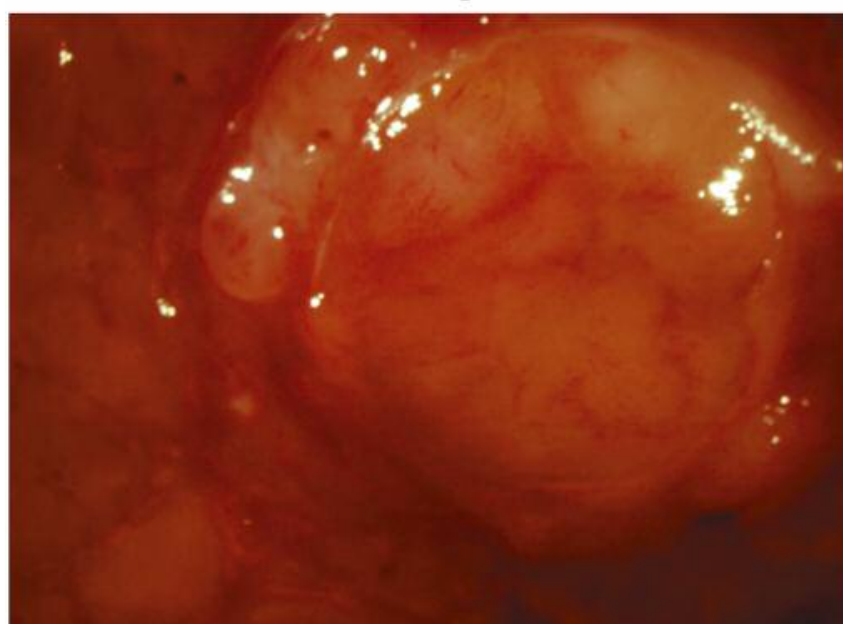

Excitation light

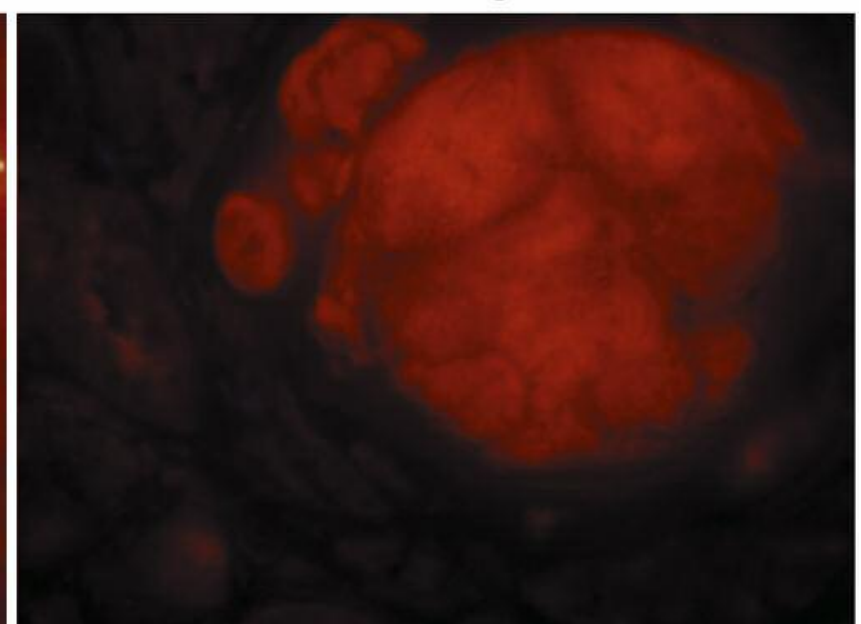

Figure 3. Red fluorescence was observed at the incision surface of resected livers, which was parallel with the location of the tumor. Imaging under white light and excitation light. 
mean age of 63.8 years (range $=51-77)$. Three patients had type $\mathrm{B}$ viral hepatitis and six patients had type $\mathrm{C}$ viral hepatitis. Except for one patient, all patients had undergone laparoscopic surgery. In 11 of the 12 patients, red fluorescence was observed at the surface of the incision in the resected liver, which was parallel with the location of the tumor (Figure 3). Fluorescence spectra with a peak of $635 \mathrm{~nm}$ were observed in these tumors using a spectral analytical system (Figure 4), which corresponds to the spectra of PpIX. Pathological diagnosis of the 11 patients who showed red fluorescence was HCC. The tumor of only one patient who underwent transcatheter arterial chemoembolization (TACE) did not show red fluorescence because their tumor had necrosed completely. Pathological examination revealed vascular and bile duct invasion in the tumor of one patient. Nine patients had chronic hepatitis and three patients had liver cirrhosis. Red fluorescence was detected regardless of vascular invasion, bile duct invasion and the liver background. Significant side-effects were not observed in this study.

\section{Discussion}

Recently, hepatic resection of HCC has improved significantly because of better surgical techniques and perioperative management. However, despite all these efforts, the long-term survival of HCC patients after surgery is still poor because of the high incidence of recurrence. The most common cause of the high recurrence rate after curative resection of $\mathrm{HCC}$ is intrahepatic recurrence. Whether intrahepatic recurrence after resection of HCC is the result of intrahepatic metastasis or multicentric occurrence of a new tumor in the liver remnant is under debate. In either case, complete removal of the tumor is one of the most important factors for long-term survival. To remove the tumor completely, correct and accurate diagnostic imaging technology is essential. Recently, the diagnosability of HCC has been improved by dynamic CT and gadoxetic acidenhanced MRI. However, there is no consistent opinion of the efficacy of diagnostic radiologic technology for small and early-stage lesions.

Imaging methods using fluorescence are clinically useful because they are simple, rapid and easily applicable. Various fluorescent probes have been used in such methods. One of the most common and long established fluorescent probes is indocyanine green that has been particularly applied to detection of liver tumors during hepatectomy $(24,25)$. This probe has good depth resolution, light intensity and sufficient safety. However, it has the greatest disadvantage of not being specific for cancer. Furthermore, although various cancerspecific fluorescent probes have been developed, clinically useful fluorescent probes are limited because these probes are not safe for use in patients.

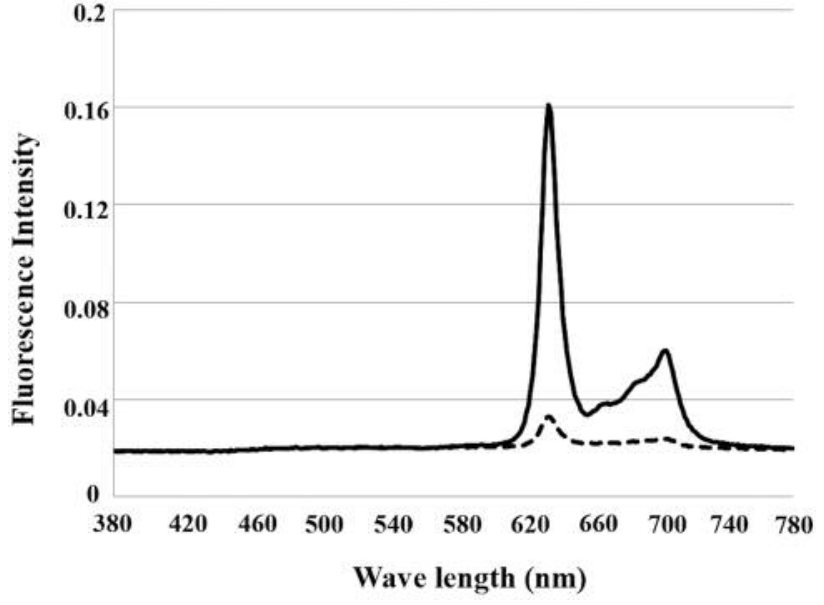

Figure 4. Spectral analysis of the tumor and the background. Solid line indicates the fluorescence spectra in the tumor and dotted line indicates the background fluorescence spectra of the liver. Fluorescence with a peak of $\sim 635 \mathrm{~nm}$ was also observed in these tumors using a spectral analytical system, which corresponds to the spectra of protoporphyrin IX (PpIX).

In this study, the red fluorescence of PpIX was observed in hepatoma cells in vitro and in vivo. Furthermore, we observed red fluorescence in HCC patients that had undergone hepatectomy. We demonstrated that 5-ALA is a sensitive and effective photosensitizer for HCC. This is the first report to evaluate the effectiveness of PDD using 5ALA for HCC in vivo, in vitro and in HCC patients. Although some previous reports have demonstrated the effectiveness of 5-ALA-PDD for other organs, there is little evidence of the utility of ALA-PDD for liver tumors. Here, we have reported the potential of 5-ALA-PDD for HCC in hepatoma cell lines, animals and clinical specimens.

5-ALA has good tumor specificity and few side-effects. Previously, 5-ALA-PDD has been used to diagnose brain tumors, such as glioma and bladder cancer (15-18). In this study, we observed the red fluorescence of 5-ALA in the specimens of all HCC patients except for one patient with a completely necrotic HCC induced by TACE. The sensitivity of 5-ALA for HCC imaging was $100 \%$.

A disadvantage of ALA-PDD is that the depth of excitation light is shallow and unsuitable for observations of deep tissue. The depth of light penetration into tissue at $630 \mathrm{~nm}$, which is used for PpIX, ranges from 0.2 to $2 \mathrm{~cm}$ $(26,27)$. We have reported previously that diagnostic methods using this wavelength of light is suitable for diagnosis of peritoneal and lymph node metastasis (19-22). However, it is difficult to diagnose tumors in deep areas of parenchymatous organs.

The intrahepatic recurrence rate after resection of HCC, especially HCC complicated by cirrhosis, is extremely high. 
Therefore, it is important to diagnose small and early-stage lesions (3). Furthermore, real-time diagnosis during liver resection plays a major role in complete curative resection because it is difficult to diagnose small and early-stage lesions preoperatively. Inoue et al. (28) detected 5-ALA fluorescence in all HCCs $(100 \%)$ with serosa invasion $(\mathrm{n}=37)$ during liver resection. In addition, the positive microscopically margin rates in terms of the resection margin width using 5-ALA-mediated PDD were lower than those using the classical method. Thus, ALA-PDD may be useful to detect small and early-stage lesions at the liver surface during liver resection.

In conclusion, we observed the red fluorescence of PpIX in HuH-7 and Hep G2 cell lines, a hepatoma mouse model and specimens from HCC patients. PDD using 5-ALA for $\mathrm{HCC}$ is simple and may be useful for real-time diagnosis during liver resection.

\section{References}

1 Akriviadis EA, Llovet JM, Efremidis SC, Shouval D, Canelo R, Ringe B and Meyers WC: Hepatocellular carcinoma. Br J Surg 85: 1319-1331, 1998

2 Rahbari NN, Mehrabi A, Mollberg NM, Müller SA, Koch M, Büchler MW and Weitz J: Hepatocellular carcinoma: current management and perspectives for the future. Ann Surg 253: 453469, 2011

3 Belghiti J, Panis Y, Farges O, Benhamou JP and Fekete F: Intrahepatic recurrence after resection of hepatocellular carcinoma complicating cirrhosis. Ann Surg 214: 114-117, 1991.

4 Grazi GL, Ercolani G, Pierangeli F, Del Gaudio M, Cescon M, Cavallari A and Mazziotti A: Improved results of liver resection for hepatocellular carcinoma on cirrhosis give the procedure added value. Ann Surg 234: 71-78, 2001.

5 Imamura H, Matsuyama Y, Miyagawa Y, Ishida K, Shimada R, Miyagawa $S$, Makuuchi $M$ and Kawasaki S: Prognostic significance of anatomical resection and desgamma- carboxy prothrombin in patients with hepatocellular carcinoma. Br J Surg 86: 1032-1038, 1999.

6 Kakazu T, Makuuchi M, Kawasaki S, Miyagawa S, Hashikura Y, Kosuge T, Takayma T and Yamamoto J: Repeat hepatic resection for recurrent hepatocellular carcinoma. Hepatogastroenterology 40: 337-341, 1993.

7 Nakajima Y, Ko S, Kanamura T, Nagao M, Nagao M, Kanehiro $\mathrm{H}$, Hisanaga M, Aomatsu Y, Ikeda $\mathrm{N}$ and Nakano $\mathrm{H}$ : Repeat liver resection for hepatocellular carcinoma. J Am Coll Surg 192: 339-344, 2001.

8 Poon RT, Fan ST, Lo CM, Liu CL and Wong J: Long-term survival and pattern of recurrence after resection of small hepatocellular carcinoma in patients with preserved liver function: implications for a strategy of salvage transplantation. Ann Surg 235: 373-382, 2002.

9 Shindoh J, Hasegawa K, Inoue Y, Ishizawa T, Nagata R, Aoki T, Sakamoto Y, Sugawara Y, Makuuchi M and Kokubo N: Risk factors of post-operative recurrence and adequate surgical approach to improve long-term outcomes of hepatocellular carcinoma. Hepatobiliary Pancreat Dis Int 15: 31-39, 2013.
10 Van Hillegersberg R, Van den Berg JW, Kort WJ, Terpstra OT and Wilson JH: Selective accumulation of endogenously produced porphyrins in a liver metastasis model in rats. Gastroenterology 103: 647-651, 1992.

11 Schoenfeld N, Epstein O, Lahav M, Mamet R, Shaklai M and Atsmon A: The heme biosynthetic pathway in lymphocytes of patients with malignant lymphoproliferative disorders. Cancer Lett 43: 43-48, 1988.

12 Dailey HA and Smith A: Differential interaction of porphyrins used in photoradiation therapy with ferrochelatase. Biochem $\mathbf{J}$ 223: 441-445, 1984.

13 Kennedy JC and Pottier RH: Endogenous protoporphyrin IX, a clinically useful photosensitizer for photodynamic therapy. J Photochem Photobiol B 14: 275-292, 1992.

14 Peng Q, Warloe T, Berg K, Moan J, Kongshaug M, Giercksky KE and Nesland JM: 5-Aminolevulinic acid-based photodynamic therapy. Clinical research and future challenges. Cancer 79: 22822308, 1997.

15 Kriegmair M, Baumgartner R, Knuchel R, Stepp H, Hofstädter $\mathrm{F}$ and Hofstetter A: Detection of early bladder cancer by 5aminolevulinic acid induced porphyrin fluorescence. J Urol 155: 105-109, 1996.

16 Jichlinski P, Forrer M, Mizeret J, Glanzmann T, Braichotte D, Wagnières G, Zimmer G, Guillou L, Schmidlin F and Graber P: Clinical evaluation of a method for detecting superficial surgical transitional cell carcinoma of the bladder by light induced fluorescence of protoporphyrin IX following the topical application of 5-aminolevulinic acid: preliminary results. Lasers Surg 20: 402-408, 1997.

17 Stummer W, Stocker S, Wagner S, Stepp H, Fritsch C, Goetz C, Goetz A, Kiefmann R and Reulen H: Intraoperative detection of malignant gliomas by 5 -aminolevulinic acid-induced porphyrin fluorescence. Neurosurgery 42: 518-526, 1998.

18 Friesen SA, Hjortland GO, Madsen SJ, Hirschberg H, Engebraten O, Nesland JM and Peng Q: 5-Aminolevulinic acidbased photodynamic detection and therapy of brain tumors (review). Int J Oncol 21: 577-582, 2002.

19 Murayama Y, Harada Y, Imaizumi K, Dai P, Nakano K, Okamoto K, Otsuji E and Takamatsu T: Precise detection of lymph node metastases in mouse rectal cancer by using 5aminolevulinic acid. Int J Cancer 125: 2256-2263, 2009.

20 Koizumi N, Harada Y, Murayama Y, Harada K, Beika M, Yamaoka Y, Dai P, Komatsu S, Kubota T, Ichikawa D, Okamoto K, Yanagisawa A, Otsuji E and Takamatsu T: Detection of metastatic lymph nodes using 5-aminolevulinic acid in patients with gastric cancer. Ann Surg Oncol 20: 35413548, 2013.

21 Kondo Y, Murayama Y, Konishi H, Morimura R, Komatsu S, Shiozaki A, Kuriu Y, Ikoma H, Kubota T, Nakanishi M, Ichikawa D, Fujiwara H, Okamoto K, Sakakura C, Takahashi K, Inoue K, Nakajima M and Otsuji E: Fluorescent detection of peritoneal metastasis in human colorectal cancer using 5aminolevulinic acid. Int J Oncol 45: 41-46, 2014.

22 Harada K, Harada Y, Beika M, Koizumi N, Inoue K, Murayama Y, Kuriu Y, Nakanishi M, Minimikawa T, Yamaoka Y, Dai P, Yanagisawa A, Otsuji E and Takamatsu T: Detection of Lymph Node Metastases in Human Colorectal Cancer by Using 5-Aminolevulinic Acid-Induced Protoporphyrin IX Fluorescence with Spectral Unmixing. Int J Mol Sci 14: 2314023152,2013 
23 Liver Cancer Study Group of Japan: The general rules for the clinical and pathological study of primary liver cancer (English edition). Tokyo: Kanehara \& Co. Ltd., 2008.

24 Aoki T, Yasuda D, Shimizu Y, Odaira M, Niiya T, Kusano T, Mitamura K, Hayashi K, Murai N, Koizumi T, Kato H, Enami Y, Miwa M and Kusano M: Image-guided liver mapping using fluorescence navigation system with indocyanine green for anatomical hepatic resection. World J Surg 32: 1763-1767, 2008.

25 Ishizawa T, Fukushima N, Shibahara J, Masuda K, Tamura S, Aoki T, Hasegawa K, Beck Y, Fukuyama M, Kokudo N: Realtime identification of liver cancers by using indocyanine green fluorescent imaging. Cancer 115: 2491-2504, 2009.

26 Webber J, Herman M, Kessel D, Fromm D: Current concepts in gastrointestinal photodynamic therapy. Ann Surg 230: 12-23, 1999.
27 Moan J, Berg K: Photochemotherapy of cancer: experimental research. Photochem Photobiol 55: 931-948, 1992.

28 Inoue $\mathrm{Y}$, Tanaka R, Komeda K, Hirokawa F, Hayashi M, Uchiyama K: Fluorescence Detection of Malignant Liver Tumors using 5-Aminolevulinic Acid-Mediated Photodynamic Diagnosis: Principles, Technique, and Clinical Experience. World J Surg 14: 2463-2469, 2014.
Received June 30, 2016

Revised July 17, 2016

Accepted July 18, 2016 